\title{
Estimation of relative source locations from seismic amplitude: application to earthquakes and tremors at Meakandake volcano, eastern Hokkaido, Japan
}

\author{
Masashi Ogiso ${ }^{1^{*}}$ (D) and Kiyoshi Yomogida ${ }^{2}$
}

\begin{abstract}
Although seismic amplitudes can be used to estimate event locations for volcanic tremors and other seismic events with unclear phase arrival times, the precision of such estimates is strongly affected by site amplification factors. Therefore, reduction of the influence of site amplification will allow more precise estimation of event locations by this method. Here, we propose a new method to estimate relative event locations using seismic amplitudes. We use the amplitude ratio between two seismic events at a given station to cancel out the effect of the site amplification factor at that station. By assuming that the difference between the hypocentral distances of these events is much smaller than their hypocentral distances themselves, we derive a system of linear equations for the differences in relative event locations. This formulation is similar to that of a master event location method that uses differences in phase arrival times. We applied our new method to earthquakes and tremors at Meakandake volcano, eastern Hokkaido, Japan. Comparison of the hypocentral distributions of volcano-tectonic earthquakes obtained thereby with those obtained from phase arrival times confirmed the validity of our new method. Moreover, our method clearly identified source migration among three source regions in the tremor on 16 November 2008, consistent with previous interpretations of other geophysical observations in our study area. Our method will thus be useful for detailed analyses of seismic events whose onset times are ambiguous.
\end{abstract}

Keywords: Relative source location, Seismic amplitude, Volcano-tectonic earthquakes, Volcanic tremors, Tremor migration, Meakandake volcano

\section{Introduction}

Estimating the location of seismic events is a fundamental step in seismological analyses. Phase arrival times are routinely used to locate earthquake hypocenters (e.g., Hirata and Matsu'ura 1987; Klein 2002). Several other techniques have been applied, some of which have dealt successfully with ambiguous arrival times. Seismic array observations (e.g., Rost and Thomas 2002) enable us to estimate wave propagation direction and apparent

\footnotetext{
*Correspondence: mogiso@mri-jma.go.jp

${ }^{1}$ Meteorological Research Institute, Japan Meteorological Agency, 1-1

Nagamine, Tsukuba 305-0052, Japan

Full list of author information is available at the end of the article
}

velocity using waveform similarity (e.g., Capon 1969; Neidell and Taner 1971; Goldstein and Archuleta 1987), which can be used to estimate a waveform's point of origin. When waveforms are not similar among stations, but seismogram envelopes are, differences in phase arrival times among stations can be estimated from seismogram envelope correlations, and source locations can be estimated from these arrival-time differences; this is known as the envelope correlation method (Obara 2002).

Seismic amplitude can also be used to estimate seismic event locations. The amplitude source location (ASL) method (e.g., Battaglia and Aki 2003; Battaglia et al. 2005; Kumagai et al. 2010) uses amplitude spatial decay for 
this purpose. Because the ASL method does not rely on phase arrival times, it is applicable to seismic events with unclear onset times, such as tremors. The ASL method has been applied to tremors and earthquakes within volcanoes (Battaglia 2003; Kumagai et al. 2011; Taisne et al. 2011; Ogiso and Yomogida 2012; Kumagai et al. 2013a; Ogiso et al. 2015; Kurokawa et al. 2016; Ichihara and Matsumoto 2017; Walsh et al. 2017; Caudron et al. 2018; Ichimura et al. 2018; Kumagai et al. 2019), pyroclastic flows (Yamasato 1997; Jolly et al. 2002), lahars or debris flows (Kumagai et al. 2009; Ogiso and Yomogida 2015; Doi and Maeda 2020), and snow avalanches (PérezGuillén et al. 2019). The ASL method has also revealed the source process of a large subduction zone earthquake (Kumagai et al. 2013b), the detailed distribution of shallow low-frequency earthquakes near a trench axis (Tamaribuchi et al. 2019). Because the ASL method uses observed seismic amplitudes, the appropriate correction of site amplification effects is important for the accuracy of event locations determined by this method (Kumagai et al. 2013a).

In addition to estimating absolute source locations, as discussed above, estimates of relative source location have been used to derive precise location distributions. The underlying concept for this techniques is the removal of common factors that affect location precisions. A joint hypocenter determination technique (e.g., Douglas 1967) includes site correction terms in a system of equations designed to simultaneously estimate relative event locations and site correction terms. A master event location method (Aoki 1974; Ito 1985; Frémont and Malone 1987) attributes differences between phase arrival times of a reference event and other events to differences in their relative locations. When seismic events occur in close proximity to one another, the errors arising from wave propagation path can be canceled out by accounting for arrival-time differences. A double-difference earthquake location algorithm (Waldhauser and Ellsworth 2000) is a novel approach to source-location estimation that uses the differences of observed and theoretical arrival times between event pairs to minimize the influence of an unmodeled heterogeneous velocity structure without any reference events. These techniques for estimating relative source locations have revealed more detailed spatial characteristics of seismicities than those by absolute location estimation methods.

Here, we propose a new method to estimate relative source locations that uses seismic amplitudes and takes advantage of aspects of both the ASL method and the relative location methods. Our method uses amplitude ratios between reference and other events at several stations to cancel out the effects of site amplification. By assuming that subevents occur near a reference event, we derive a system of linear equations for differences in relative location. We then estimate relative locations by solving the equations with a standard least-squares method. In this paper, we first explain the formulation of our new method and then apply it to volcano-tectonic (VT) earthquakes and tremors at Meakandake volcano, eastern Hokkaido, Japan. To test the validity of our method, we then compare the hypocentral distribution of VT earthquakes derived by our new method with those derived by two methods that determine hypocenters from phase arrival times. Next, we demonstrate that the migration of the tremor locations that we identified with our new method is clearer than that in the previous study (Ogiso and Yomogida 2012), and discuss the relationship between tremor source regions and other geophysical observations.

\section{Theoretical background}

In this section, we briefly review the ASL method and then present the theory that underpins our new method of determining relative source locations from seismic amplitudes.

\section{ASL method}

When body waves propagate, the observed seismic amplitude $A^{(i)}(f)$ at a certain frequency $f$ at the $i$ th station can be represented as

$$
A^{(i)}(f)=A^{(s)}(f) \frac{\exp \left(-B(f) r^{(i)}\right)}{r^{(i)}} S^{(i)}(f),
$$

where $A^{(s)}(f)$ is the source radiation amplitude, $r^{(i)}$ the hypocentral distance between the source and the $i$ th station, and $S^{(i)}(f)$ the site amplification factor at the $i$ th station. $B(f)$ is defined as

$$
B(f)=\frac{\pi f}{Q \beta},
$$

where $Q$ is the intrinsic attenuation factor and $\beta$ the velocity of the medium, or the average $\mathrm{S}$-wave velocity in general. If we assume the source location for a certain event, we can calculate the source radiation amplitude $A^{(s)}(f)$ as

$$
A^{(s)}(f)=\frac{1}{N} \sum_{i=1}^{N} \frac{A^{(i)}(f)}{S^{(i)}(f)} r^{(i)} \exp \left(B(f) r^{(i)}\right),
$$

where $N$ is the number of observations. Using Eqs. (1) and (3), we calculate the normalized residual $R$ as

$$
R=\frac{\sum_{i=1}^{N}\left\{A^{(i)}(f) / S^{(i)}(f)-A^{(s)}(f) \exp \left(-B(f) r^{(i)}\right) / r^{(i)}\right\}^{2}}{\sum_{i=1}^{N}\left\{A^{(i)}(f) / S^{(i)}(f)\right\}^{2}} .
$$


In application of the ASL method, a grid search is usually conducted to find the location where $R$ reaches its minimum value. Because the heterogeneous radiation pattern of the source is not modeled in Eq. (1), and because distortion of the radiation pattern becomes more obvious in higher frequency ranges (e.g., Takemura et al. 2009; Kobayashi et al. 2015), seismic amplitudes at high frequencies (usually higher than $5 \mathrm{~Hz}$ ) are suitable for the ASL method.

\section{Estimation of relative source locations from seismic amplitudes}

As shown by Eq. (3), the site amplification factor $S^{(i)}(f)$ has a large influence on source locations estimated by the ASL method. The coda normalization method (e.g., Phillips and Aki 1986; Takemoto et al. 2012) is widely used to estimate site amplification factors. Calibration of site amplification factors with seismic events for which locations are well constrained (Ichihara and Matsumoto 2017; Walsh et al. 2017; Kumagai et al. 2019) is preferable when estimating source locations. Nevertheless, some uncertainties are unavoidable when estimating site amplification factors. In this study, we propose the use of amplitude ratios to cancel out uncertainties in site amplification factors.

From Eq. (1), the amplitude ratio between two events, the $j$ th and $k$ th events, at the $i$ th station is

$$
\frac{A_{k}^{(i)}(f)}{A_{j}^{(i)}(f)}=\frac{A_{k}^{(s)}(f)}{A_{j}^{(s)}(f)} \frac{\exp \left(-B(f) r_{k}^{(i)}\right)}{\exp \left(-B(f) r_{j}^{(i)}\right)} \frac{r_{j}^{(i)}}{r_{k}^{(i)}},
$$

where $A_{j}^{(i)}(f)$ and $A_{k}^{(i)}(f)$ are the observed amplitudes of the $j$ th and $k$ th events at the $i$ th station, $A_{j}^{(s)}(f)$ and $A_{k}^{(s)}(f)$ are the source radiation amplitudes of the $j$ th and $k$ th events, respectively, and $r_{j}^{(i)}$ and $r_{k}^{(i)}$ are the hypocentral distances from the $i$ th station to the $j$ th and $k$ th events, respectively. We define the difference between the hypocentral distances of the $j$ th and $k$ th events with respect to the $i$ th station $\Delta r_{j k}^{(i)}$ as

$$
\Delta r_{j k}^{(i)}=r_{k}^{(i)}-r_{j}^{(i)},
$$

and, substituting Eq. (6) into (5) gives

$$
\frac{A_{k}^{(i)}(f)}{A_{j}^{(i)}(f)}=\frac{A_{k}^{(s)}(f)}{A_{j}^{(s)}(f)} \exp \left(-B(f) \Delta r_{j k}^{(i)}\right)\left(1+\frac{\Delta r_{j k}^{(i)}}{r_{j}^{(i)}}\right)^{-1} .
$$

Here we assume that the sources of the $j$ th and $k$ th events are near each other so that $\Delta r_{j k}^{(i)}$ becomes much smaller than the hypocentral distances $r_{j}^{(i)}$ and $r_{k}^{(i)}$. Taking the natural logarithm of both sides of Eq. (7) and approximating $\ln \left(1+\Delta r_{j k}^{(i)} / r_{j}^{(i)}\right)$ as $\Delta r_{j k}^{(i)} / r_{j}^{(i)}$, Eq. (7) becomes

$$
\ln \frac{A_{k}^{(i)}(f)}{A_{j}^{(i)}(f)} \approx \ln \frac{A_{k}^{(s)}(f)}{A_{j}^{(s)}(f)}-B(f) \Delta r_{j k}^{(i)}-\frac{\Delta r_{j k}^{(i)}}{r_{j}^{(i)}} .
$$

Similar to the formulation of Aoki (1974) for a master event location method using differences of phase arrival times, we can approximate $\Delta r_{j k}^{(i)}$ to be

$$
\Delta r_{j k}^{(i)} \approx \mathbf{n}_{j}^{(i)} \cdot \Delta \mathbf{x}_{j k},
$$

where $\mathbf{n}_{j}^{(i)}$ is the unit vector representing the takeoff angle and azimuth from the $j$ th event to the $i$ th station, and $\Delta \mathbf{x}_{j k}$ is the location vector of the $k$ th event relative to the $j$ th event. This approximation is valid for direct waves. After substituting Eq. (9) into (8), we rewrite Eq. (8) into the following matrix form for standard least-square inversion:

$$
\mathbf{d}=\mathbf{G m}
$$

where d represents the data vector consisting of $\ln \left(A_{k}^{(i)} / A_{j}^{(i)}\right), \mathbf{m}$ is the model vector consisting of $\ln \left(A_{k}^{(s)} / A_{j}^{(s)}\right)$ and $\Delta \mathbf{x}_{j k}$, and $\mathbf{G}$ is the kernel consisting of the coefficients of the model vector in the right-hand side of Eq. (8). We can solve Eq. (10) by a standard leastsquares method if we have more than four observations for each event. Our formulation is essentially the same as that of the master event location method using differences of phase arrival times (Aoki 1974), except we use seismic amplitudes rather than arrival times.

The corresponding model covariance matrix $\mathbf{S}_{m}$ is

$$
\mathbf{S}_{m}=\left(\mathbf{G}^{T} \mathbf{S}_{d}^{-1} \mathbf{G}\right)^{-1},
$$

where $\mathbf{S}_{d}$ is the data covariance matrix. In the following analysis, we first calculate the variance of data residuals using all events except the reference event. Assuming that errors in the data are independent each other, we construct a diagonal data covariance matrix with the variance of data residuals to obtain $\mathbf{S}_{m}$ by Eq. (11). Because we adopt a common value for variance for all data, the estimation errors of relative source locations derived by Eq. (11) become the same for all events.

Ichihara and Matsumoto (2017) estimated relative locations of volcanic tremor events using seismic amplitude ratios. They calculated amplitude ratios among several stations to eliminate the source radiation amplitude term $\left(A^{(s)}(f)\right.$ in Eq. 1) and conducted a grid search to find optimal tremor source locations. It appears that the approach of Ichihara and Matsumoto (2017) estimates relative source locations, because the site amplification terms and intrinsic attenuation factor they used were adjusted to the reference source location. Nevertheless, their principle formulation follows the original ASL method. In 
contrast, we attribute the amplitude ratio between two events at each station to the relative difference between their locations. Our approach relies on the assumption that the difference between the hypocentral distance of a reference event and a subevent is much smaller than their hypocentral distances, which is not required in the formulation of Ichihara and Matsumoto (2017). Our formulation thus has two advantages over theirs. First, we avoid uncertainties in estimating site amplification factors. Second, our fundamental formulation (Eq. 8) has a simple linear form, so that we can estimate not only relative source locations, but also the errors on those estimations using a standard least-squares method.

\section{Data and analysis}

Meakandake volcano (eastern Hokkaido, northern Japan; Fig. 1a) has three active craters: Naka-machineshiri,
Pon-machineshiri, and Mt. Akanfuji. The eruptive history of Meakandake (Japan Meteorological Agency 2013) shows that its most recent eruption was a phreatic eruption in November 2008 at the 96-1 crater, on the southeastern edge of the Pon-machineshiri crater (Ishimaru et al. 2009). Many earthquakes and tremors were observed before and during the 2008 eruptive period (Ogiso and Yomogida 2012; Japan Meteorological Agency 2013). In this study, we used seismograms of VT earthquakes and volcanic tremors recorded during the 2008 activity at Meakandake by five stations (Fig. 1a) operated by the Sapporo Regional Volcano Observation and Warning Center (RVOWC) of the Japan Meteorological Agency. Vertical-component short-period (natural period $1 \mathrm{~s}$ ) seismometers were deployed at stations V.PMNS and V.NSYM, and three-component shortperiod ( $1 \mathrm{~s})$ seismometers were deployed at the other
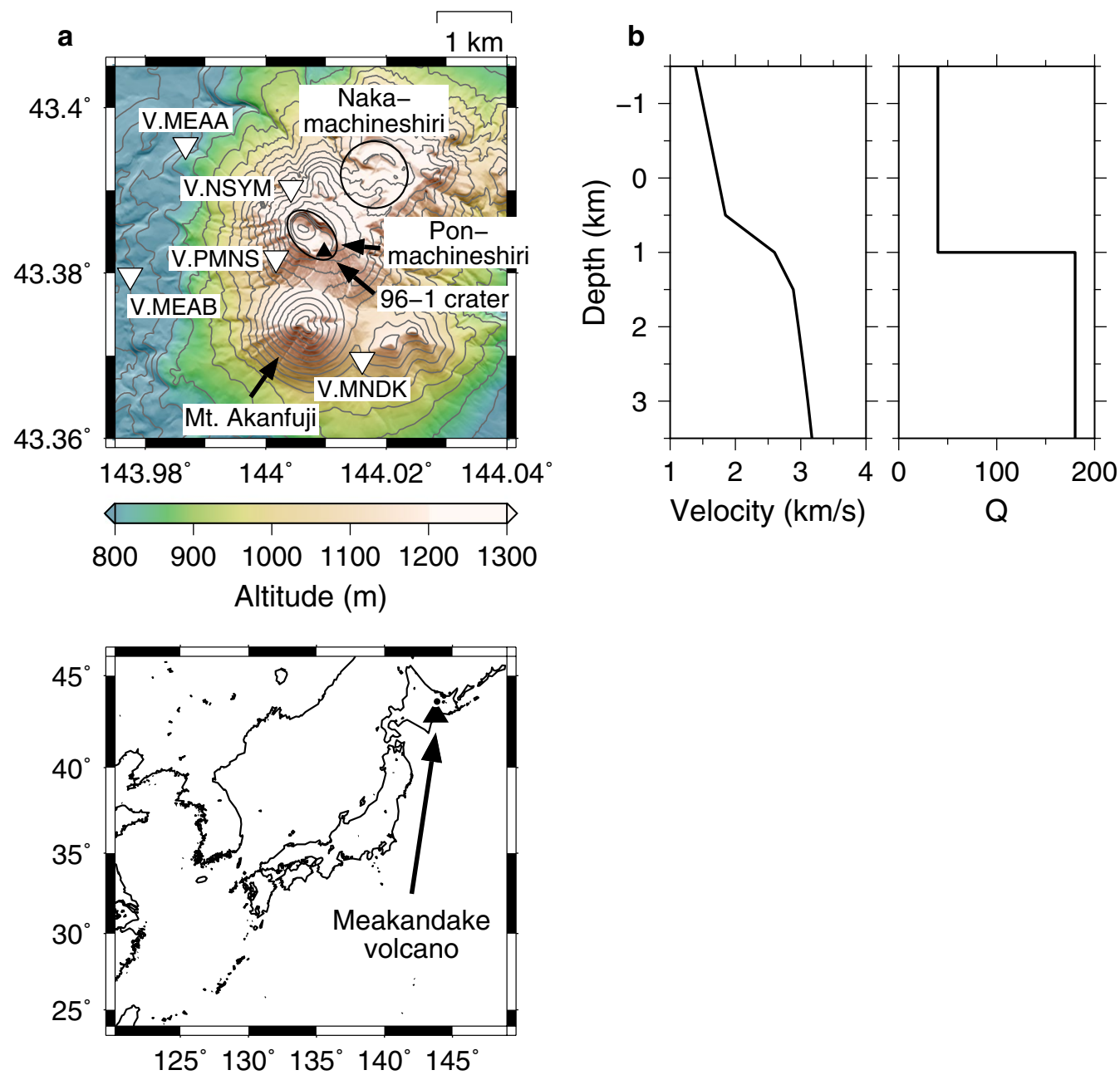

Fig. 1 a Regional location map (below) and topographic map (above) of Meakandake volcano showing the locations of the five seismic stations (inverted triangles) used in this study. Topographic contour interval is $50 \mathrm{~m}$. b One-dimensional S-wave velocity (left) and attenuation (right) structures used in this study. The origin of the depth is mean sea level 
three stations. Each seismogram was digitized at a sampling rate of $0.01 \mathrm{~s}$.

In this study, we used 1-D velocity and attenuation structure of S-waves shown in Fig. 1b. The velocity structure was derived by trial-and-error approach at Sapporo RVOWC, which has been used there for routine hypocenter determinations since August 2017 (Okuyama, 2020, personal communication). The attenuation structure we used is that of Kumagai et al. (2019), which they used in their application of the ASL method at Nevado del Ruiz volcano (Colombia). We modified the depth of the boundary of the attenuation structure of Kumagai et al. (2019) to be consistent with the velocity structure at Meakandake volcano. We conducted a ray shooting in a spherical coordinate (e.g., Aki and Richards 1980, Chapter 13) to derive $\mathbf{n}_{j}^{(i)}$ in Eq. (9).

To validate the source locations of the VT earthquakes determined by our new method by comparing them with those determined from phase arrival times, we selected 45 earthquake events that occurred near the 96-1 crater between 1 and 10 November 2008 for which the Sapporo RVOWC had determined hypocenters from phase arrival times. We manually picked up the arrival times of $\mathrm{P}$-waves at all five stations and those of S-waves at stations V.MEAB and V.MNDK (Fig. 2). Note that because the phase arrivals for these earthquakes were clearly evident on all of the seismograms, any event location method using phase arrival times would be suitable for further analysis of this seismic activity. We calculated source locations by three methods: (a) absolute hypocenter estimation from phase arrival times with the HYPOMH algorithm (Hirata and Matsu'ura 1987), (b) master event location estimation (Aoki 1974) using differences of P-wave arrival times, (c) ASL method using seismic amplitudes and (d) our new method of estimating relative source locations. The reference event we used for the two methods of estimating relative source locations was an earthquake at 21:30 (Japan Standard Time; JST) on 7 November 2008 (latitude $43.3829^{\circ}$, longitude $144.0093^{\circ}$, depth -0.40 $\mathrm{km})$. This reference location was originally determined from the phase arrival times and the HYPOMH algorithm. We selected this reference event because its epicenter was at the centroid of all of the hypocenters derived from the phase arrival times. The P-wave velocity structure we used for the HYPOMH algorithm and master event method was $\sqrt{3}$ times larger than S-wave velocity structure shown in Fig. 1b. For the ASL and our relative source location methods, we applied a 5-10 $\mathrm{Hz}$ bandpass filter to the data of each seismogram, and calculated the root-mean-square (RMS) amplitude of the vertical component within a time window extending for $10 \mathrm{~s}$ after the P-wave arrival (Fig. 2). The time

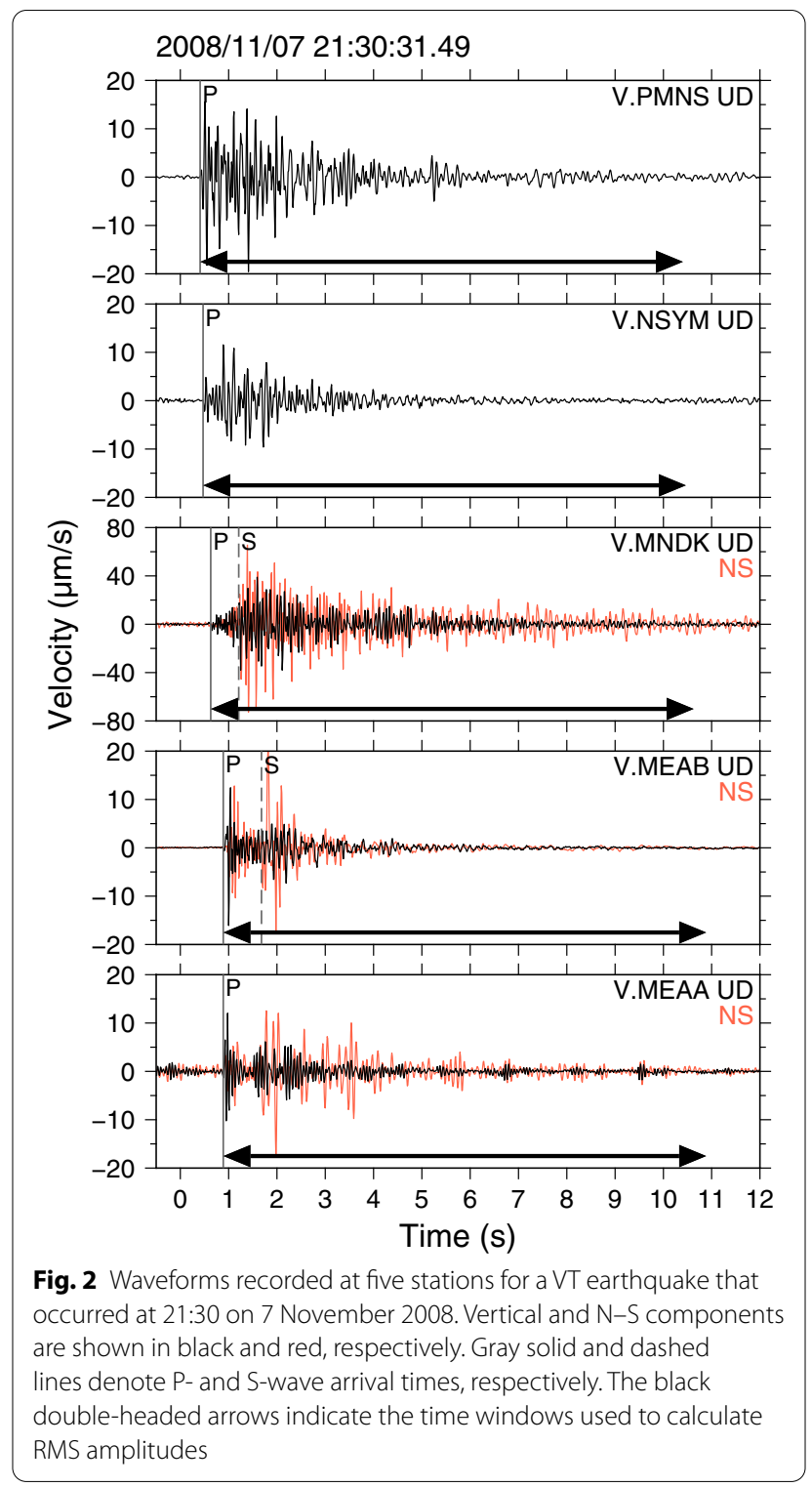

window includes the whole waveform record of the VT earthquake so that direct, narrow- and wide-angle scattered waves affect the RMS amplitude. The amplitude of late-arriving coda waves, that is, that of wide-angle scattered waves, is so small that the direct and narrowangle scattered waves mainly contribute to the obtained RMS amplitude at each station. Although our formulation presented in the previous section is rigorously valid only for direct waves, the formulation still holds for the RMS amplitudes because the takeoff angle and azimuth of narrow-angle scattered waves can be considered to be very close to those of the direct waves (Sato and Emoto 2018). We set frequency $f$ in Eq. (2) to $7.5 \mathrm{~Hz}$. For the ASL method, we used the same 
amplification factors as those estimated by Ogiso and Yomogida (2012) using the coda normalization method, and performed a grid search with $0.001^{\circ}$ increments of latitude and longitude and a $0.1 \mathrm{~km}$ depth increment. Because the reference event located on the shallower layer with $Q=40$, we used the value in our new method regardless of the two-layer attenuation structure (Fig. 1b).

For comparison of the calculated volcanic tremor locations, we selected tremors that occurred on 16 and 17 November 2008. Ogiso and Yomogida (2012) applied the ASL method to these events and identified segmentation in their source regions. The duration time of 16 November tremor was about $30 \mathrm{~min}$ (Ogiso and Yomogida 2012). Following the approach of Ogiso and Yomogida (2012), we divided the first $17 \mathrm{~min}$ of the tremor into three phases (Fig. 3a) and estimated source locations for each phase. During 17 and 18 November, small-amplitude, long-duration tremors were observed intermittently (Ogiso and Yomogida 2012, Fig. 18). Because amplitude ratios among stations did not change significantly during these intermittent tremors (Ogiso and Yomogida 2012, Fig. 21), we estimated tremor locations from 11:00 to 12:00 (JST) on 17 November (Fig. 3b). Because the velocity and attenuation structures we used (Fig. 1b) differed from the simple structures used by Ogiso and Yomogida (2012), we analyzed the locations of these tremors by both the ASL method and our new relative source location method. The process we used to prepare amplitude data was similar to that used for analysis of volcanic earthquakes, apart from the length of the time window. After applying a 5-10 Hz bandpass filter, we calculated the time series of RMS amplitudes from the vertical-component seismogram at each station within a 30-s time window that we shifted by $15 \mathrm{~s}$ for each calculation. We then used these time series of RMS amplitudes for
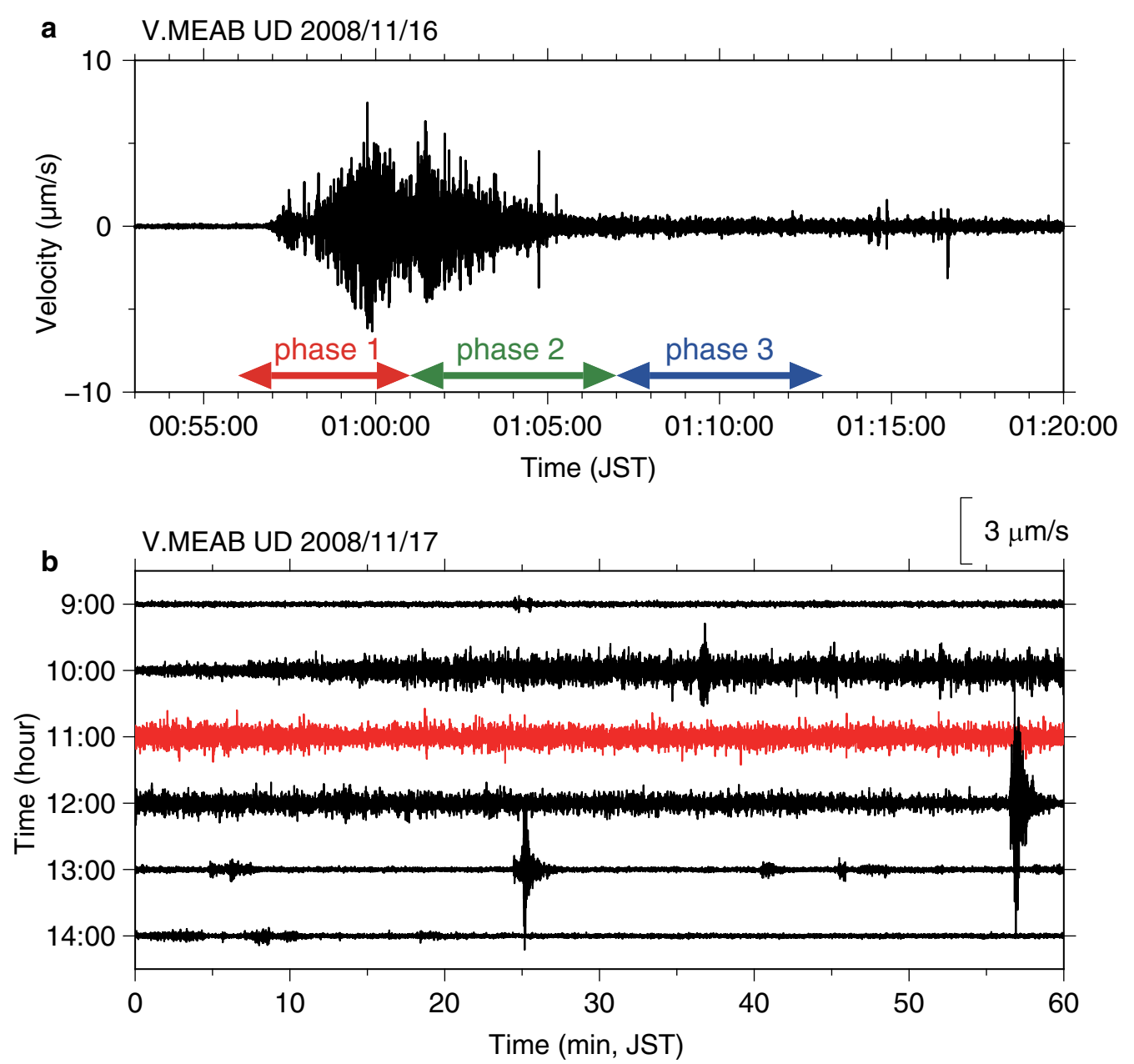

Fig. 3 Vertical component of tremor waveforms recorded at station V.MEAB on a 16 November and b 17 November 2008. We estimated tremor locations for the waveforms shown in red in $\mathbf{b}$. Note that both waveforms were decimated without anti-aliasing filtering to reduce the file size of the figure 
both the ASL and our relative source location methods. For our relative source location method, we set the reference location for tremors of both 16 and 17 November at latitude $43.378^{\circ}$, longitude $144.005^{\circ}$ and $0.1 \mathrm{~km}$ depth, which was the tremor location from 01:05:05 to 01:05:35 (JST) on 16 November, as estimated by the ASL method in this study. Same as the case of VT earthquakes, we used $f=7.5(\mathrm{~Hz})$ and $Q=40$ in our method. The calculation procedure of the ASL method for the tremors was the same as that for the VT earthquakes.

\section{Results and discussions}

\section{Synthetic test}

Equation (8) requires the condition $\Delta r_{j k}^{(i)} \ll r_{j}^{(i)}$, but the condition may not be satisfied with small-aperture seismic networks such as that used in this study (Fig. 1). Hence, we conducted a synthetic test to estimate the systematic error when $\Delta r_{j k}^{(i)}$ was not significantly smaller than $r_{j}^{(i)}$. We assumed source amplitudes and locations of 11 events, one for a reference and the others for its subevents. We calculated theoretical amplitudes at each station with the seismic structure shown in Fig. 1b, then estimated the relative source location of each subevent. Figure 4 shows the result of the synthetic test. The maximum distance between assumed and estimated source locations was about $0.54 \mathrm{~km}$ for the subevents that located within about $1.3 \mathrm{~km}$ from the reference event. Two events with interevent distances of about $0.7 \mathrm{~km}$ and
$1 \mathrm{~km}$ showed large discrepancies (larger than $0.5 \mathrm{~km}$ ) between the correct and estimated source locations. Although the two events which located near the stations would be affected by the violation of the condition $\Delta r_{j k}^{(i)} \ll r_{j}^{(i)}$, the systematic error of $0.54 \mathrm{~km}$ can still be acceptable for us to monitor the seismicity at Meakandake volcano. We concluded the distance of 1.3 $\mathrm{km}$ to be the threshold of distance between the reference event and subevent in this study.

\section{VT earthquakes}

Comparison of the hyopcenter distributions of VT earthquakes estimated by the four considered source-location methods (Fig. 5) shows that the focal region derived from phase arrival times extends about $0.5 \mathrm{~km}$ horizontally and $1.2 \mathrm{~km}$ vertically (Fig. 5a), and that derived by our relative source location method extends about 1.0 $\mathrm{km}$ horizontally and $1.3 \mathrm{~km}$ vertically (Fig. $5 \mathrm{~d}$ ). The focal region derived by the master event method on the basis of differences of P-wave arrival times (Fig. 5b) had the smallest extent among the three results: about $0.2 \mathrm{~km}$ horizontally and $0.6 \mathrm{~km}$ vertically. We note that the absolute source locations by the master event method and our relative source location method (Fig. 5b, d) depended on the location of the selected reference event. The hypocenter distribution estimated by the ASL method (Fig. 5c) shows large discrepancies from those by the other three methods. There should be some reasons for these

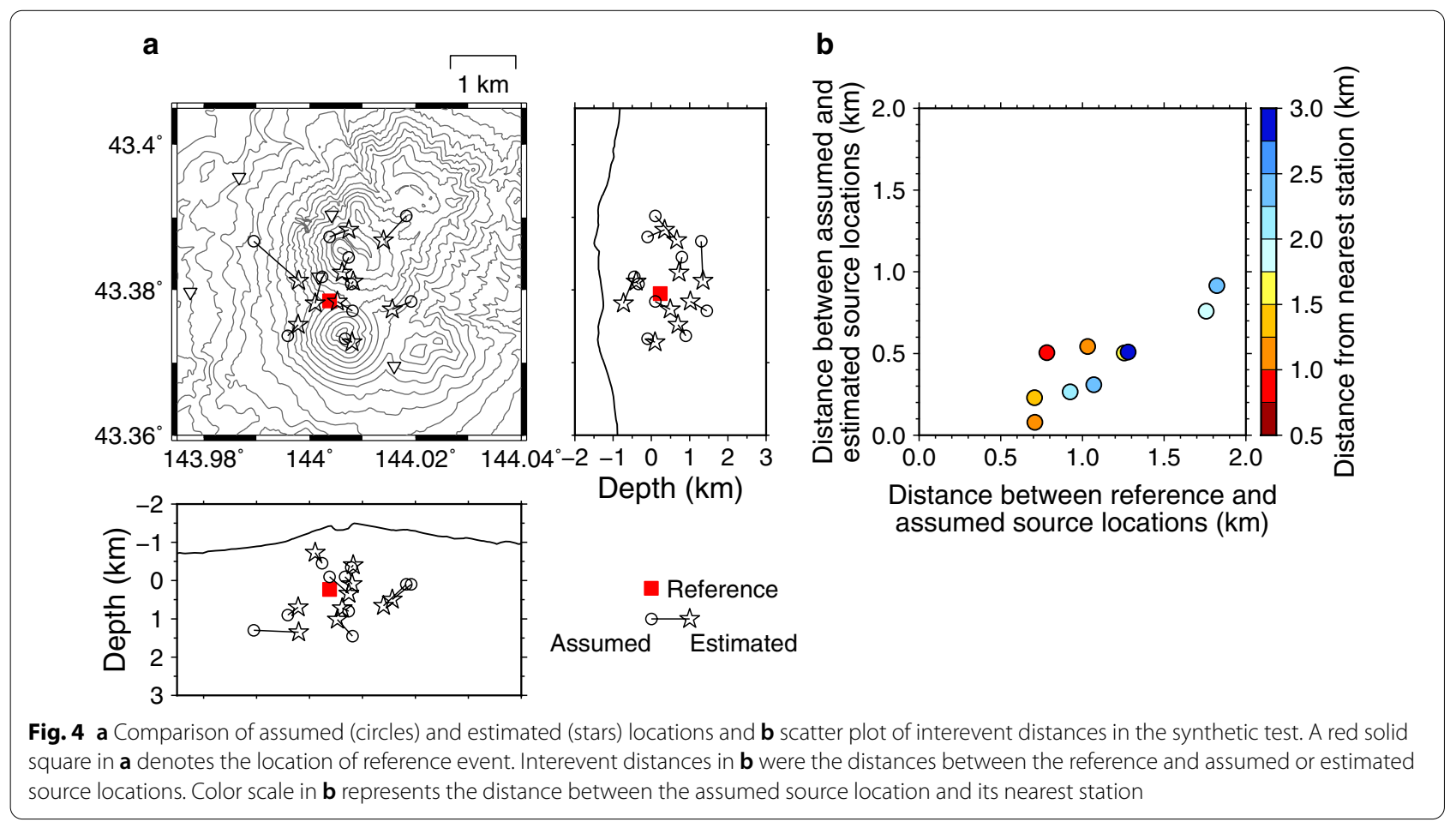



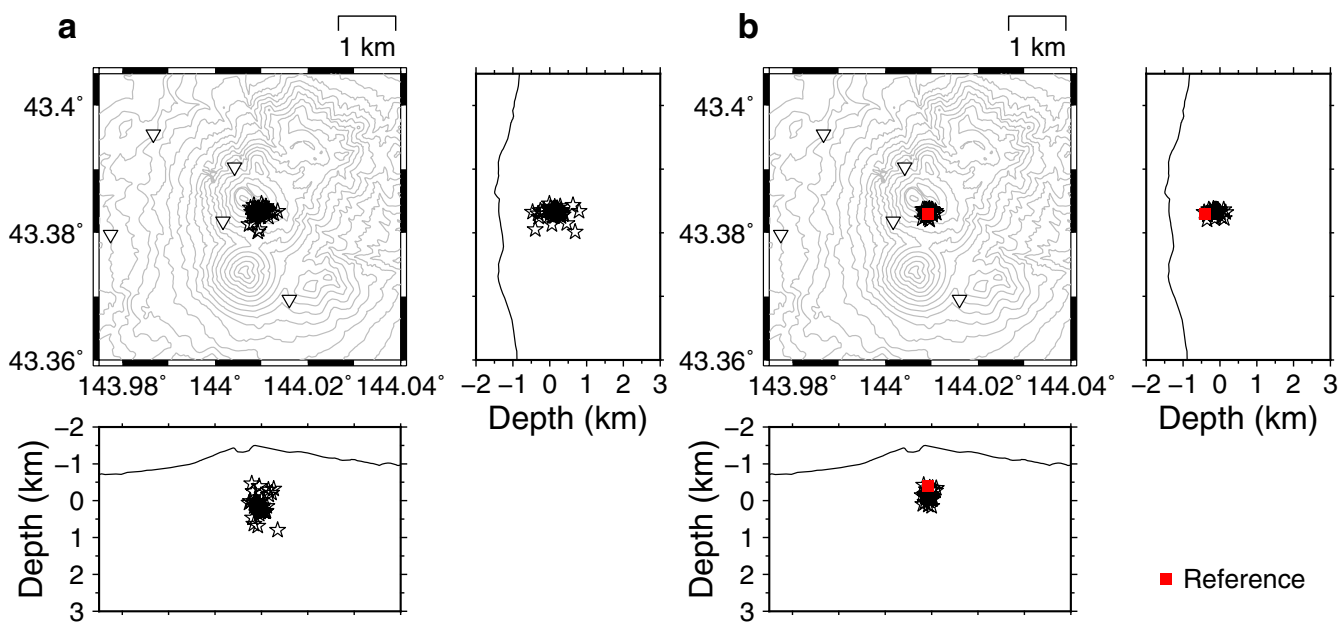

- Reference
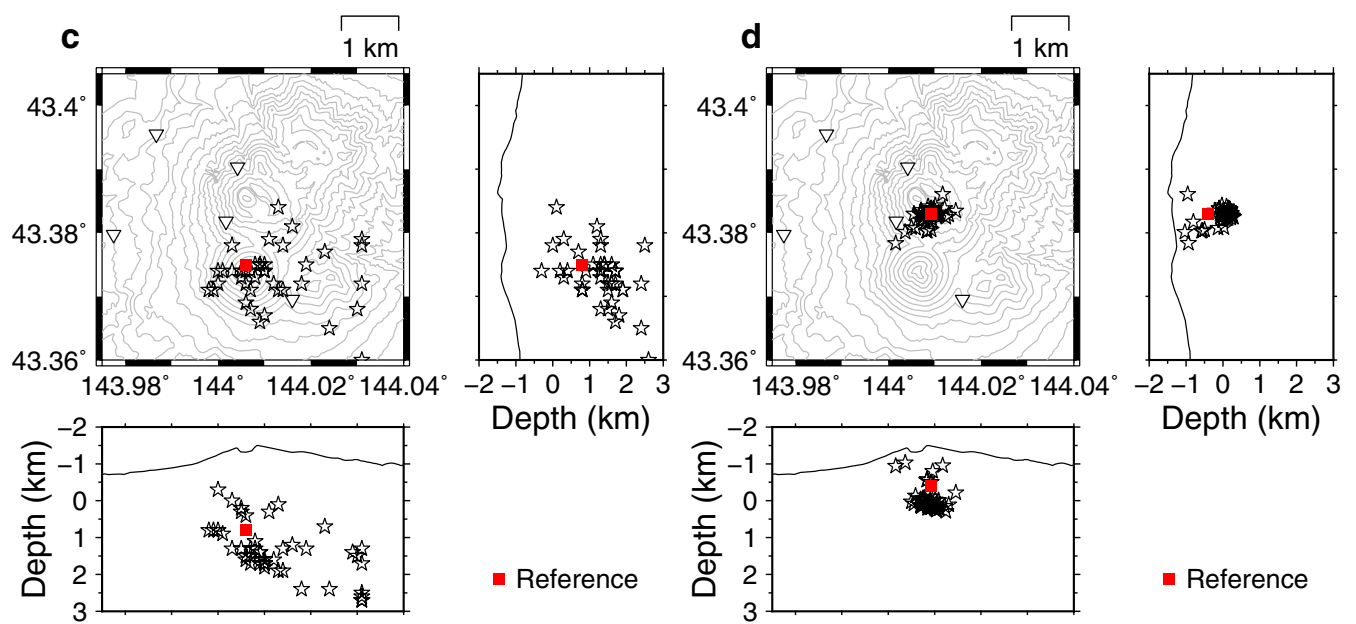

- Reference

Fig. 5 Plan and vertical cross-sectional views of the hypocenter distributions of VT earthquakes from 1 to 10 November 2008 derived from a phase arrival times and the HYPOMH algorithm, $\mathbf{b}$ the master event method using differences of P-wave arrival times, $\mathbf{c}$ the ASL method and $\mathbf{d}$ our relative source location method. In the plan views, inverted triangles denote seismic stations, and elevation contours are at $50 \mathrm{~m}$ intervals. Red solid squares denote the location of the reference event for estimation of relative source locations and calculation of interevent distances. Location errors of $\mathbf{d}$ calculated by Eq. (11) were about $0.002^{\circ}$ for latitude and longitude, and $0.2 \mathrm{~km}$ in depth

discrepancies, but we do not discuss them in this paper. Figure 6 compares the interevent distances between reference and other events. The interevent distances by the ASL method range from 0.34 to $3.4 \mathrm{~km}$ while 0.29 to 0.97 $\mathrm{km}$ by our new method, indicating the great improvement by our new method (Fig. 6a). The RMS difference between interevent distances of the master event method and ours is $0.29 \mathrm{~km}$ (Fig. 6b), which probably shows the intrinsic location errors of our new method for VT earthquakes at Meakandake volcano. This value is remarkably small compared with the ASL method.

The depth distributions of source locations differ slightly between the HYPOMH, master event, and our methods. The source-depth distribution derived from the
HYPOMH algorithm seems to have a mean of about 0.25 $\mathrm{km}$ (Fig. 5a). That derived by the master event method shows most of the sources to be concentrated at about $0 \mathrm{~km}$ depth (Fig. 5b). In contrast, the source-depth distribution derived by our relative source location method (Fig. 5c) shows two clusters: the one at depths from 0 to $0.3 \mathrm{~km}$ and the other at depths less than about $-0.5 \mathrm{~km}$. The shallow cluster has larger variations in horizontal location than the deep one. This segmentation of location depths was not found by these two methods with phase arrival times (Fig. 5a, b). This apparent depth segmentation may be due to two different focal mechanisms. Because the onsets of P- and S-waves for these events were clearly evident in seismograms, their radiation 

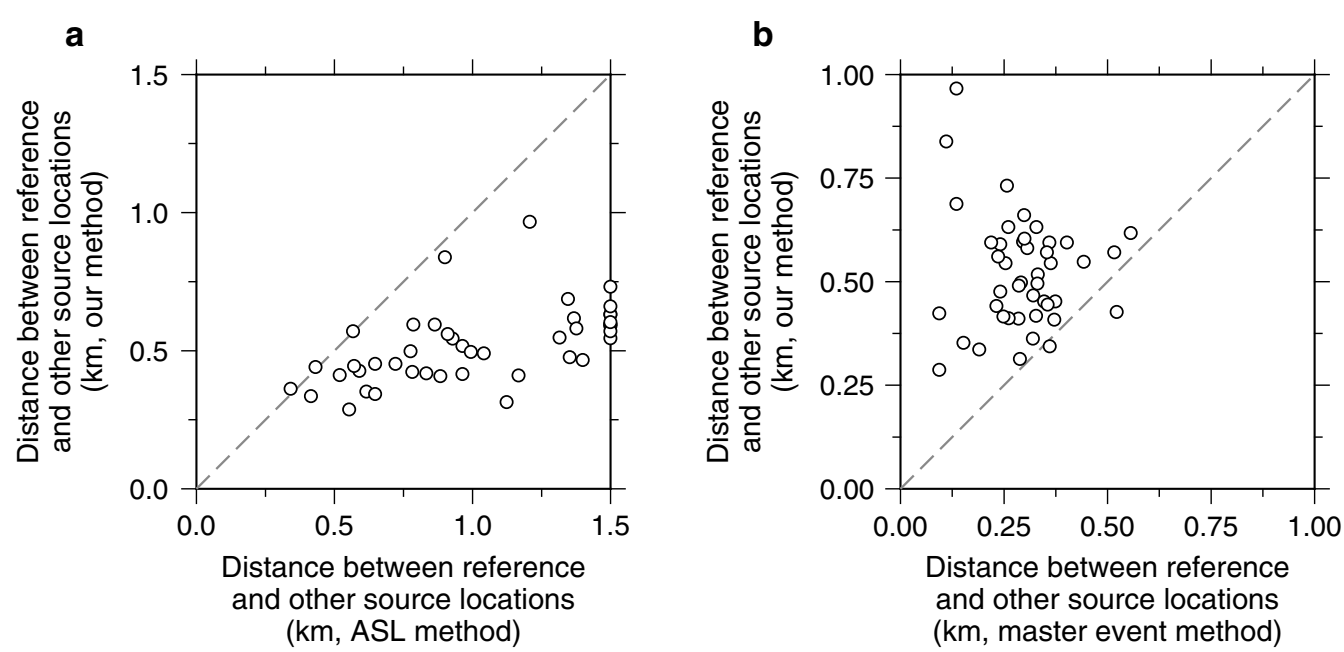

Fig. 6 Comparison between estimated interevent distances of $\mathbf{a}$ the ASL and our methods and $\mathbf{b}$ the master event and our methods. The interevent distances were distances from the reference event shown as red solid squares in Fig. 5. Interevent distances of longer than $1.5 \mathrm{~km}$ were clipped in a

patterns should not be isotropic. Amplitude ratio (Eq. 5) may diverge if a given station is located at a nodal plane exactly of either two events. Narrow-angle seismic scattering process compensates the amplitude at a nodal plane (Takemura et al. 2009; Kobayashi et al. 2015) so that we can generally measure a stable amplitude ratio even in such a station. Because of its stochastic process, hypocentral distance is an important factor in this compensation of amplitudes. Takemura et al. (2016) showed that the degree of this compensation depends on the hypocentral distance normalized by the wavenumber of seismic waves. Because of their relatively short hypocentral distance in this study (Fig. 5), the compensation may not be enough particularly for VT earthquakes in which seismic energy is concentrated in a short time window. In this case, amplitude ratio at a certain station may become unstable, then such an apparent segmentation in a focal region may occur. If the focal mechanisms of the two events were similar to each other, their spatial distributions of seismic amplitude should also be similar, so the amplitude ratios of the two events well reflect the differences between their source radiation amplitudes and their relative source locations (i.e., Eq. 5) regardless of the amplitude compensation by narrow-angle scattered waves. For events with different focal mechanisms, the amplitude ratios would be dependent on the azimuth of each station. Under such circumstances, the importance of the compensation becomes large for an appropriate estimation of relative source locations by our method. Distortion or reduction of radiation patterns due to multiple scattering of seismic waves (Takemura et al. 2009; Kobayashi et al. 2015) has important ramifications for the ability of our method to stably locate seismic events with different focal mechanisms, as is also the case for the ASL method (Morioka et al. 2017). If the focal mechanisms among events are similar to each other, the relative source locations estimated by seismic amplitude ratios will be equally as reliable as the absolute source locations estimated from phase arrival times, regardless of the scattering properties of the medium.

The choice of attenuation structure affected the extent of the focal region for our relative source location method. Equation (8) indicates that an observed amplitude ratio can be decomposed into the ratio of the source radiation amplitude and the difference in relative source location. Variable $B$ in Eq. (8) (i.e., the intrinsic attenuation factor in the region of the reference event) determines the contribution of the difference between relative locations to the observed amplitude ratio. Figure 7 shows the hypocentral distribution estimated by our method with different $Q$ values $(Q=20$ and 100). If $Q$ is large, the contribution of the difference between relative locations becomes small and the distribution of relative source locations widens (Fig. 7b). In contrast, the relative source locations converge toward zero with a small value of $Q$ (Fig. 7a). Because the type of the 2008 eruption was phreatic (Ishimaru et al. 2009; Japan Meteorological Agency 2013), there should not have been a strong-attenuated region such as magma chamber in a shallow part, and $Q=20$ seemed to be unrealistic for Meakandake volcano. The overall feature of hypocenters of $Q=40$ (Fig. 5d) and $Q=100$ (Fig. 7b) was similar to each other, and the improvement in hypocenter location is common in both $Q$ values compared with the conventional ASL 

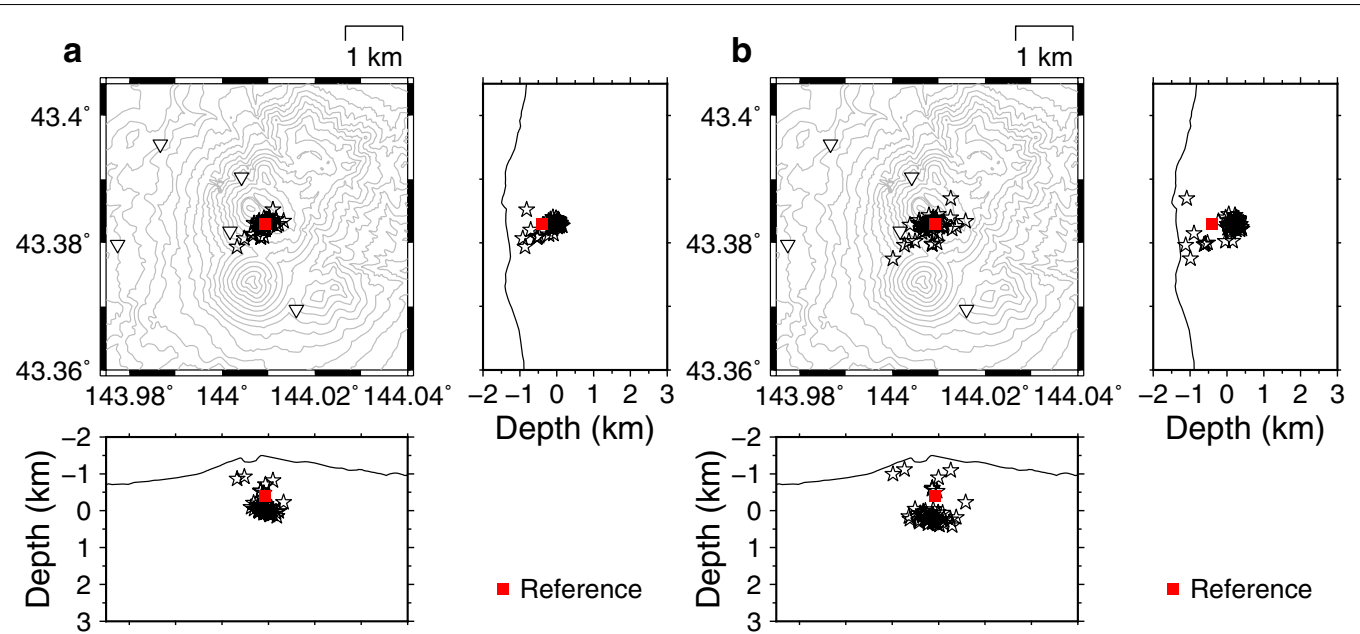

- Reference

Fig. 7 Plan and vertical cross-sectional views of the hypocenter distributions of $\mathrm{VT}$ earthquakes with $\mathbf{a} Q=20$ and $\mathbf{b} Q=100$

method. The difference in hypocenter loation between $Q=40$ and $Q=100$ was small so that we used the results of $Q=40$ for the rest of this study. Ideally, the attenuation structure around the target focal region should be evaluated independently by some other methods, such as simultaneous inversion of the source, attenuation and site amplification terms (e.g., Oth et al. 2011; Nakano et al. 2015). Use of a detailed 3-D heterogeneous attenuation structure around a source region (e.g., Matsumoto et al. 2009) would greatly improve the precision of our source location method.

\section{Tremors of 16 and 17 November}

We now compare the distribution of source locations of volcanic tremors estimated by our method with that estimated by the ASL method. We assumed that the tremors on 16 and 17 November had no clear azimuthal dependency in their spatial distributions of seismic amplitudes. Tremors, which have relatively continuous signals, should be less affected by differences in focal mechanism than the dominant $\mathrm{P}$ - and $\mathrm{S}$-wave arrivals of VT earthquakes.

There is a clear southwest to northeast horizontal trend of source locations in all four results (Fig. 8), but their horizontal extents differ. The horizontal extent of source locations obtained using the ASL method are from 1.0 km (Fig. 8c) to $1.5 \mathrm{~km}$ (Fig. 8a), whereas those obtained using our new method are from $0.8 \mathrm{~km}$ (Fig. $8 \mathrm{~d}$ ) to 1.0 $\mathrm{km}$ (Fig. 8b). Because there are no stations in the southwest or northeast of the source region of the tremors, the trend is originated from the distribution of stations. Fig. 8 clearly shows that our method significantly reduced this artificial trend in comparison with the ASL method.

Ogiso and Yomogida (2012) found that the tremor locations on 16 November migrated among phases 1,
2 , and 3 , and that the spatial distribution of phase 3 of the 16 November tremor overlapped those of the following intermittent long-duration tremors on 17 to 18 November. The tremor locations we estimated by the ASL method (Fig. 5a, c) show similar characteristics as those of Ogiso and Yomogida (2012, Figs. 15 and 20). They interpreted the location differences of the tremor on 16 November represented downward migration of the tremor source during phases 1 and 2, and that the source region of phase 3 connected the source regions of phases 1 and 2 with those of the following intermittent tremors.

The relative source locations estimated by our new method (Fig. 8b, d) show similar overall characteristics to those estimated by the ASL method (Fig. 8a, c), but the detail of the spatial relationships of source regions for the three phases of tremor on 16 November differ as follows (Fig. 8a, b). Our method showed the source region of the phase 1 tremor to be more tightly concentrated on the western flank of Mt. Akanfuji, with those of phases 2 and 3 a little farther to the northeast of the phase 1 source region, but not extending as far to the northeast as those estimated by the ASL method. In particular, the source region of the phases 2 and 3 overlapped each other. The source region of the tremor of 17 November estimated by our new method was the east of the source regions of the tremor of 16 November, and there was no overlap of the source regions of the events on those two days. This difference between the spatial relationships of the source regions of tremors estimated by the ASL method and our new method may partly reflect to the uncertainty of the site amplification correction in the ASL method. If the site amplification factor at one station differed greatly from its true value, the source radiation amplitude (Eq. 3) would also 

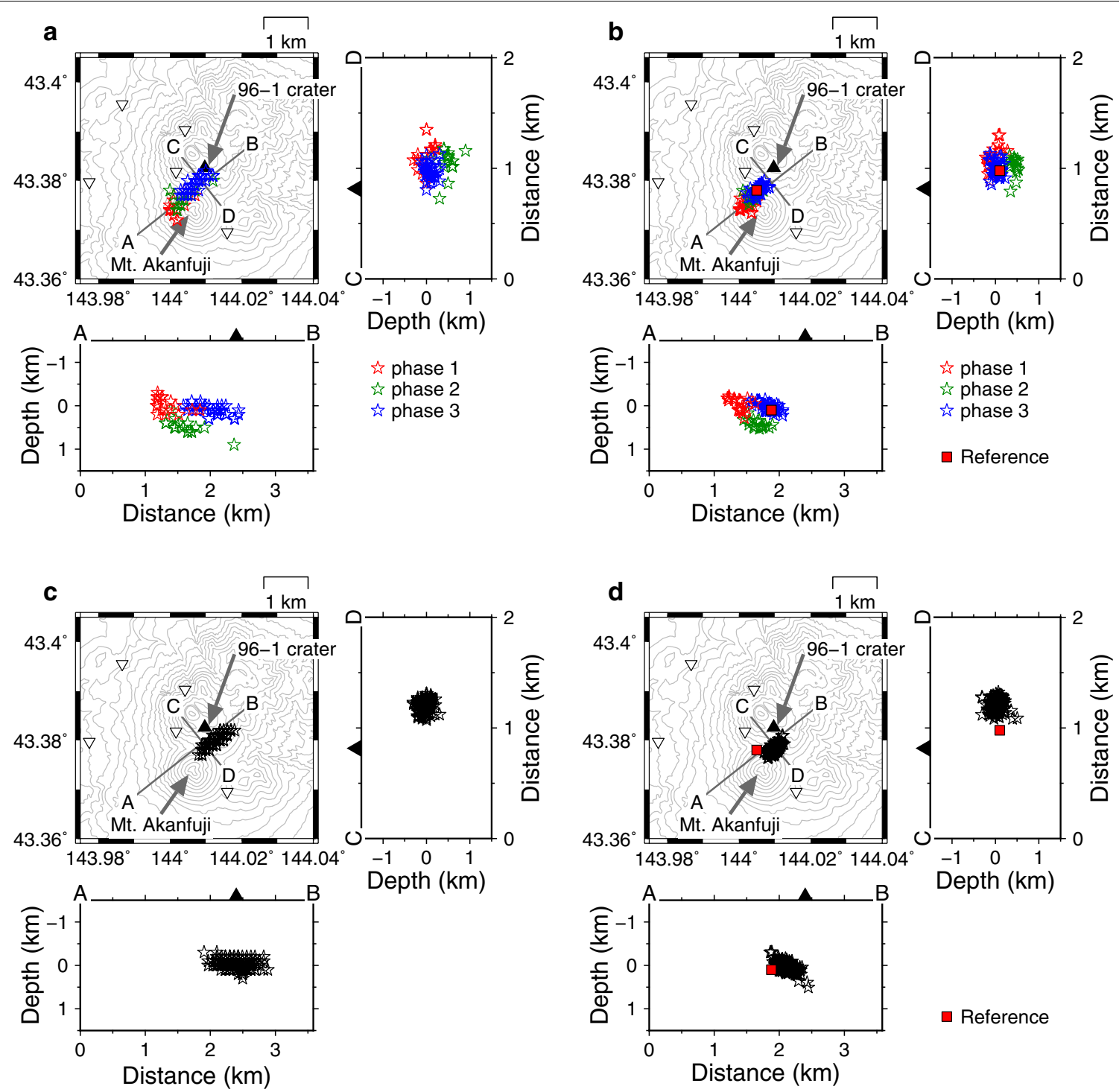

Fig. 8 Locations of the tremors of $\mathbf{a}, \mathbf{b} 16$ and $\mathbf{c}, \mathbf{d} 17$ November as estimated by $\mathbf{a}, \mathbf{c}$ the ASL method and $\mathbf{b}$, $\mathbf{d}$ our new location method. The two vertical cross-sectional views show the tremor locations along line A-B (lower panel) and line C-D (right panel), respectively. In $\mathbf{a}$ and $\mathbf{b}$, the red, green, and blue stars indicated source locations for the three phases indicated by the same colors in Fig. $3 \mathrm{a}$. Red solid squares in $\mathbf{b}$ and $\mathbf{d}$ show the reference location for our method. Location errors of $\mathbf{b}$ and $\mathbf{d}$ were about $0.001^{\circ}$ for latitude and longitude, and less than $0.2 \mathrm{~km}$ in depth

differ from its true value, and the ASL method would then estimate an incorrect source location. If there were many observations (stations), an error in site amplification factor at a single station would be suppressed because Eq. (3) uses the average of site-corrected amplitudes at all stations. However, the smaller the number of observations (we used only five stations), the larger the influence of each observation on the location estimated by the ASL method. In contrast, our relative source location method minimizes the effect of such errors in site amplification corrections for estimation of source locations. The difference between the source locations derived by the ASL and those derived by our new method demonstrate the ability of our method to cancel out the uncertainties of site amplification factors when there are few stations.

Takahashi et al. (2018) found a region of low resistivity located beneath the northwest flank of Mt. Akanfuji from audio-frequency magnetotelluric observations, which corresponds to the source regions we identified for three tremor phases on 16 November (Fig. 8b). On the basis of broadband seismic observations, Aoyama and Oshima (2015) retrieved the change of tilt that they attributed to the opening of a vertical crack in the volcanic edifice. 
To explain the change of tilt, Takahashi et al. (2018) proposed a model in which upward heat convection caused the rapid flow of heat into the low-resistivity zone. Migration of the source location, as estimated by the ASL method for the tremor of 16 November, appears to be inconsistent with the model of Takahashi et al. (2018): the descent of the source location between phases 1 and 2 conflicts with the upward heat transfer of their model. In contrast, the relative locations in this study by applying our new method are consistent with their model: the source region of the phase 1 is consistent the activation of volcanic fluids in the low-resistivity zone, and the ascent of source locations between phases 2 and 3 is consistent to the rapid transfer of heat from depth.

The locations of the sources of the intermittent tremors (on 17 November) remains controversial. The locations we estimated by the ASL method (Fig. 8c) indicate that the source region of the intermittent tremors partially overlaps that of the phase 3 of the tremor on 16 November (Fig. 8a), whereas our new relative source location method separates the source regions of the two tremors (Fig. 8b, d). Based on the source locations estimated by our method, there may have some mechanism by which the two source regions were linked, although no geophysical evidence to support this link has yet come to light. Future improvements in geophysical observation networks around active volcanic craters and greater precision in the location of tremor sources will likely help us to understand the cause of such separations of source regions.

\section{Conclusions}

We have presented a new method to estimate relative source locations from seismic amplitudes. The method is similar to the conventional master event method except that it uses event amplitude ratios instead of phase arrival times. Our method avoids the uncertainties inherent in the estimation of site amplification factors using amplitude ratios between two events at a common station. We assume that for two events near to each other, the observed amplitude ratios can be attributed to the ratio of source radiation amplitude and the difference of relative source location in the form of standard least-squares inversions that we can use to estimate not only relative source locations, but also their errors. The relative source locations of VT earthquakes estimated by our new method showed that using seismic amplitude ratios enabled us to derive a hypocentral distribution similar to that determined by the conventional absolute source location method using phase arrival times. We applied our new method to estimate relative source locations for volcanic tremors recorded at Meakandake volcano on 16 and 17 November 2008, and identified clear segmentation of source clusters and migration of tremor source locations. The observed migration is consistent with other geophysical observations, such as the resistivity structure and changes in tilt determined from broadband seismic data. Our new method of source location from event amplitude data will be useful for detailed analyses of seismic events whose onset times are ambiguous.

\section{Abbreviations \\ ASL: Amplitude source location; VT:Volcano-tectonic; RMS: Root mean square; RVOWC: Regional Volcano Observation and Warning Center; JST: Japan standard time. \\ Acknowledgements \\ Sapporo RVOWC provided the waveform data that we used in this study. We used the digital elevation data compiled by the Geospatial Information Authority of Japan. We thank Satoshi Okuyama at Sapporo RVOWC for giving us information about velocity structure at Meakandake volcano and helpful discussions about hypocenter distributions. Careful reviews and helpful com- ments from two anonymous reviewers improved the manuscript. All figures were drawn with the Generic Mapping Tools version 5 (Wessel et al. 2013).}

\section{Authors' contributions}

$\mathrm{MO}$ estimated source locations and drafted the manuscript. $\mathrm{KY}$ formulated the equations and discussed the results with MO. Both authors read and approved the final manuscript.

Funding

Not applicable.

\section{Availability of data and materials}

The waveform data we analyzed are available from the corresponding author on request. The source codes used in this study can be downloaded from https://github.com/mogiso/AmplitudeSourceLocation.

Ethics approval and consent to participate Not applicable.

Consent for publication

Not applicable.

Competing interests

The authors declare that they have no competing interests.

\section{Author details}

${ }_{1}^{1}$ Meteorological Research Institute, Japan Meteorological Agency, 1-1 Nagamine, Tsukuba 305-0052, Japan. ${ }^{2}$ Department of Earth and Planetary Science, Faculty of Science, Hokkaido University, North 10 West 8, Kita-ku, Sapporo 060-0810, Japan.

Received: 16 October 2020 Accepted: 20 January 2021

Published online: 29 January 2021

\section{References}

Aki K, Richards PG (1980) Quantitative seismology volume 1 and 2, 1 st edn. W. H. Freeman and Company, San Francisco

Aoki H (1974) Plate tectonics of arc-junction at central Japan. J Phys Earth 22(1):141-161. https://doi.org/10.4294/jpe1952.22.141

Aoyama H, Oshima H (2015) Precursory tilt changes of small phreatic eruptions of Meakan-dake volcano, Hokkaido, Japan, in November 2008. Earth Planets Space. https://doi.org/10.1186/s40623-015-0289-9

Battaglia J (2003) Location of long-period events below Kilauea Volcano using seismic amplitudes and accurate relative relocation. J Geophys Res 108(B12):2553. https://doi.org/10.1029/2003JB002517 
Battaglia J, Aki K (2003) Location of seismic events and eruptive fissures on the Piton de la Fournaise volcano using seismic amplitudes. J Geophys Res 108(B8):2364. https://doi.org/10.1029/2002JB002193

Battaglia J, Aki K, Ferrazzini V (2005) Location of tremor sources and estimation of lava output using tremor source amplitude on the Piton de la Fournaise volcano: 1. Location of tremor sources. J Volcanol Geotherm Res 147(3-4):268-290. https://doi.org/10.1016/j.jvolgeores.2005.04.005

Capon J (1969) High-resolution frequency-wavenumber spectrum analysis. Proc IEEE 57(8):1408-1418. https://doi.org/10.1109/PROC.1969.7278

Caudron C, White RS, Green RG, Woods J, Ágústsdóttir T, Donaldson C, Greenfield T, Rivalta E, Brandsdóttir B (2018) Seismic amplitude ratio analysis of the 2014-2015 Bárð̈arbunga-Holuhraun dike propagation and eruption. J Geophys Res Solid Earth 123(1):264-276. https://doi.org/10.1002/2017J B014660

Doi I, Maeda T (2020) Landslide characteristics revealed by high-frequency seismic waves from the 2017 landslide in central Japan. Seismol Res Lett 91(5):2719-2729. https://doi.org/10.1785/0220200032

Douglas A (1967) Joint epicentre determination. Nature 215(5096):47-48. https://doi.org/10.1038/215047a0

Frémont MJ, Malone SD (1987) High precision relative locations of earthquakes at Mount St. Helens, Washington. J Geophys Res Solid Earth 92(B10):10223-10236. https://doi.org/10.1029/JB092iB10p10223

Goldstein P, Archuleta RJ (1987) Array analysis of seismic signals. Geophys Res Lett 14(1):13-16. https://doi.org/10.1029/GL014i001p00013

Hirata N, Matsu'ura M (1987) Maximum-likelihood estimation of hypocenter with origin time eliminated using nonlinear inversion technique. Phys Earth Planet Interiors 47(C):50-61. https://doi.org/10.1016/00319201(87)90066-5

Ichihara M, Matsumoto S (2017) Relative Source Locations of Continuous Tremor Before and After the Subplinian Events at Shinmoe-dake, in 2011. Geophys Res Lett 44(21):10,871-10,877. https://doi.org/10.1002/2017G L075293

Ichimura M, Yokoo A, Kagiyama T, Yoshikawa S, Inoue H (2018) Temporal variation in source location of continuous tremors before ash-gas emissions in January 2014 at Aso volcano, Japan. Earth Planets Space 70(1):125. https ://doi.org/10.1186/s40623-018-0895-4

Ishimaru S, Tamura M, Hirose W, Murayama Y, Okazaki N, Shibata T, Nakagawa M, Yoshimoto M, Hasegawa K, Uesawa S, Nishimoto J, Kosugi A, Matsumoto A, Baba A, Sasaki H, Takahashi H, Ichiyanagi M, Yamaguchi T, Kohno Y, Honda R, Kasahara M, Sapporo District Meteorological Observatory, Kushiro Local Meteorological Observatory, Abashiri Local Meteorological Observatory (2009) Preliminary report on the eruption on November 2008 of Meakandake volcano. Rep Geol Surv Hokkaido 80:115-126 (In Japanese with English figure captions)

Ito A (1985) High resolution relative hypocenters of similar earthquakes by cross-spectral analysis method. J Phys Earth 33(4):279-294. https://doi. org/10.4294/jpe1952.33.279

Japan Meteorological Agency (2013) National catalog of the active volcanoes in Japan (the 4th edition, English version). URL https://www.data.jma. go.jp/svd/vois/data/tokyo/STOCK/souran_eng/menu.htm. Accessed 16 Oct 2020

Jolly A, Thompson G, Norton G (2002) Locating pyroclastic flows on Soufriere Hills Volcano, Montserrat, West Indies, using amplitude signals from high dynamic range instruments. J Volcanol Geotherm Res 118(3-4):299-317. https://doi.org/10.1016/S0377-0273(02)00299-8

Klein FW (2002) User's guide to HYPOINVERSE-2000, a Fortran program to solve for earthquake locations and magnitudes. US Geological Survey Open-File Report (02-171):1-123. https://doi.org/10.3133/ofr02171

Kobayashi M, Takemura S, Yoshimoto K (2015) Frequency and distance changes in the apparent P-wave radiation pattern: effects of seismic wave scattering in the crust inferred from dense seismic observations and numerical simulations. Geophys J Int 202(3):1895-1907. https://doi. org/10.1093/gji/ggv263

Kumagai H, Palacios P, Maeda T, Castillo DB, Nakano M (2009) Seismic tracking of lahars using tremor signals. J Volcanol Geotherm Res 183(1-2):112121. https://doi.org/10.1016/j.jvolgeores.2009.03.010

Kumagai H, Nakano M, Maeda T, Yepes H, Palacios P, Ruiz M, Arrais S, Vaca M, Molina I, Yamashina T (2010) Broadband seismic monitoring of active volcanoes using deterministic and stochastic approaches. J Geophys Res Solid Earth 115(8):1-21. https://doi.org/10.1029/2009JB006889
Kumagai H, Placios P, Ruiz M, Yepes H, Kozono T (2011) Ascending seismic source during an explosive eruption at Tungurahua volcano. Ecuador. Geophys Res Lett 38(1):2-6. https://doi.org/10.1029/2010GL045944

Kumagai H, Lacson R, Maeda Y, Figueroa MS, Yamashina T, Ruiz M, Palacios P, Ortiz H, Yepes H (2013a) Source amplitudes of volcano-seismic signals determined by the amplitude source location method as a quantitative measure of event size. J Volcanol Geotherm Res 257:57-71. https://doi. org/10.1016/j.jvolgeores.2013.03.002

Kumagai H, Pulido N, Fukuyama E, Aoi S (2013b) High-frequency source radiation during the 2011 Tohoku-Oki earthquake, Japan, inferred from KiK-net strong-motion seismograms. J Geophys Res Solid Earth 118(1):222-239. https://doi.org/10.1029/2012JB009670

Kumagai H, Londoño JM, Maeda Y, Acevedo Rivas AE (2019) amplitude source location method with depth-dependent scattering and attenuation structures: application at Nevado del Ruiz Volcano, Colombia. J Geophys Res Solid Earth 124(11):11585-11600. https://doi.org/10.1029/2019J B018156

Kurokawa A, Takeo M, Kurita K (2016) Two types of volcanic tremor changed with eruption style during 1986 Izu-Oshima eruption. J Geophys Res Solid Earth 121(4):2727-2736. https://doi.org/10.1002/2015JB012500

Matsumoto S, Uehira K, Watanabe A, Goto K, lio Y, Hirata N, Okada T, Takahashi H, Shimizu H, Shinohara M, Kanazawa T (2009) High resolution $Q^{-1}$ estimation based on extension of coda normalization method and its application to P-wave attenuation structure in the aftershock area of the 2005 West Off Fukuoka Prefecture Earthquake (M7.0). Geophys J Int 179(2):1039-1054. https://doi.org/10.1111/j.1365-246X.2009.04313.x

Morioka H, Kumagai H, Maeda T (2017) Theoretical basis of the amplitude source location method for volcano-seismic signals. J Geophys Res Solid Earth 122(8):6538-6551. https://doi.org/10.1002/2017JB013997

Nakano K, Matsushima S, Kawase H (2015) Statistical properties of strong ground motions from the generalized spectral inversion of data observed by K-NET, KiK-net, and the JMA Shindokei network in Japan. Bull Seismol Soc Am 105(5):2662-2680. https://doi.org/10.1785/0120140349

Neidell NS, Taner MT (1971) Semblance and other coherency measures for multichannel data. Geophysics 36(3):482-497. https://doi. org/10.1190/1.14401868

Obara K (2002) Nonvolcanic deep tremor associated with subduction in southwest Japan. Science 296(5573):1679-1681. https://doi.org/10.1126/ science. 1070378

Ogiso M, Yomogida K (2012) Migration of tremor locations before the 2008 eruption of Meakandake Volcano, Hokkaido, Japan. Journal of Volcanology and Geothermal Research 217-218:8-20. https://doi.org/10.1016/j. jvolgeores.2011.12.0050

Ogiso M, Yomogida K (2015) Estimation of locations and migration of debris flows on Izu-Oshima Island, Japan, on 16 October 2013 by the distribution of high frequency seismic amplitudes. J Volcanol Geotherm Res 298:15-26. https://doi.org/10.1016/j.jvolgeores.2015.03.015

Ogiso M, Matsubayashi H, Yamamoto T (2015) Descent of tremor source locations before the 2014 phreatic eruption of Ontake volcano, Japan. Earth Planets Space 67(1):206. https://doi.org/10.1186/s40623-015-0376-y

Oth A, Bindi D, Parolai S, Di Giacomo D (2011) Spectral analysis of K-NET and KiK-net data in Japan, Part II: on attenuation characteristics, source spectra, and site response of borehole and surface stations. Bull Seismol Soc Am 101(2):667-687. https://doi.org/10.1785/0120100135

Pérez-Guillén C, Tsunematsu K, Nishimura K, Issler D (2019) Seismic location and tracking of snow avalanches and slush flows on Mt. Fuji, Japan. Earth Surf Dyn 7(4):989-1007. https://doi.org/10.5194/esurf-7-989-2019

Phillips WS, Aki K (1986) Site amplification of coda waves from local earthquakes from local earthquakes in central California. Bull Seismol Soc Am 76(3):627-648

Rost S, Thomas C (2002) Array seismology: methods and applications. Rev Geophys. https://doi.org/10.1029/2000RG000100

Sato H, Emoto K (2018) Synthesis of a scalar wavelet intensity propagating through von Kármán-type random media: radiative transfer theory using the born and phase-screen approximations. Geophys J Int 215:909-923. https://doi.org/10.1093/gii/ggy319

Taisne B, Brenguier F, Shapiro NM, Ferrazzini V (2011) Imaging the dynamics of magma propagation using radiated seismic intensity. Geophys Res Lett 38(4):2-6. https://doi.org/10.1029/2010GL046068

Takahashi K, Takakura S, Matsushima N, Fujii I (2018) Relationship between volcanic activity and shallow hydrothermal system at Meakandake volcano, 
Japan, inferred from geomagnetic and audio-frequency magnetotelluric measurements. JVolcanol Geotherm Res 349:351-369. https://doi. org/10.1016/j.jvolgeores.2017.11.019

Takemoto T, Furumura T, Saito T, Maeda T, Noguchi S (2012) Spatial- and frequency-dependent properties of site amplification factors in Japan derived by the coda normalization method. Bull Seismol Soc Am 102(4):1462-1476. https://doi.org/10.1785/0120110188

Takemura S, Furumura T, Saito T (2009) Distortion of the apparent S-wave radiation pattern in the high-frequency wavefield: Tottori-Ken Seibu, Japan, earthquake of 2000. Geophys J Int 178(2):950-961. https://doi. org/10.1111/j.1365-246X.2009.04210.X

Takemura S, Kobayashi M, Yoshimoto K (2016) Prediction of maximum P- and S-wave amplitude distributions incorporating frequency- and distancedependent characteristics of the observed apparent radiation patterns 4. Seismology. Earth Planets Space. https://doi.org/10.1186/s4062 3-016-0544-8

Tamaribuchi K, Kobayashi A, Nishimiya T, Hirose F, Annoura S (2019) Characteristics of Shallow Low-Frequency Earthquakes off the Kii Peninsula, Japan, in 2004 Revealed by Ocean Bottom Seismometers. Geophys Res Lett 46(23):13737-13745. https://doi.org/10.1029/2019GL085158
Waldhauser F, Ellsworth WL (2000) A double-difference earthquake location algorithm: method and application to the northern Hayward Fault, California. Bull Seismol Soc Am 90(6):1353-1368. https://doi. org/10.1785/0120000006

Walsh B, Jolly AD, Procter J (2017) Calibrating the amplitude source location (ASL) method by using active seismic sources: an example from Te Maari volcano, Tongariro National Park, New Zealand. Geophys Res Lett 44(8):3591-3599. https://doi.org/10.1002/2017GL073000

Wessel P, Smith WHF, Scharroo R, Luis J, Wobbe F (2013) Generic mapping tools: improved version released. Eos Trans Am Geophys Union 94(45):409-410. https://doi.org/10.1002/2013EO450001

Yamasato H (1997) Quantitative analysis of pyroclastic flows using infrasonic and seismic data at Unzen Volcano, Japan. J Phys Earth 45(6):397-416. https://doi.org/10.4294/jpe1952.45.397

\section{Publisher's Note}

Springer Nature remains neutral with regard to jurisdictional claims in published maps and institutional affiliations.

\section{Submit your manuscript to a SpringerOpen ${ }^{\circ}$ journal and benefit from:}

- Convenient online submission

- Rigorous peer review

- Open access: articles freely available online

- High visibility within the field

- Retaining the copyright to your article

Submit your next manuscript at $\boldsymbol{\nabla}$ springeropen.com 